\title{
Entrepreneurs Seeking Gains: Profit Motives and Risk Aversion in Inventors' Commercialization Decisions
}

\author{
Kenneth L. Simons \\ Department of Economics \\ Rensselaer Polytechnic Institute \\ $1108^{\text {th }}$ Street \\ Troy, NY 12180-3590 \\ United States \\ Tel.: (518) 276-3296 \\ Email: simonk@rpi.edu \\ Thomas Åstebro \\ HEC Paris \\ 1 Rue de la Liberation \\ 78351 Jouy en Josas \\ France \\ Tel.: +3313967 717463 \\ Email: Åstebro@hec.fr
}

March 2010

Suggested running head: Entrepreneurs Seeking Gains

Åstebro acknowledges financial support from the Natural Sciences and Engineering Research Council of Canada and the Social Sciences and Humanities Research Council of Canada's joint program in Management of Technological Change, the Canadian Imperial Bank of Commerce, and the MINE program, and in-kind support from the Canadian Innovation Centre/Waterloo. We appreciate comments from Matthias Benz, Simon Board, Steven Klepper, Andrew Oswald, Tom Poot, anonymous referees, and seminar participants at the 2002 Schumpeter Society, the 2003 DRUID Conference, the 2003 ZEW Workshop on Empirical Economics of Innovation and Patenting, the 2006 International Industrial Organization Conference, and RPI. 


\title{
Entrepreneurs Seeking Gains: Profit Motives and Risk Aversion in Inventors' Commercialization Decisions
}

\begin{abstract}
$\underline{\text { Abstract }}$
Direct evidence has been lacking on entrepreneurs' response to individual-specific opportunities, and recent work suggests that entrepreneurship may be a non-profit-seeking activity and that entrepreneurs evaluate risk oddly. We model heterogeneous inventors and inventions, outside opportunities, sunk and non-sunk costs, and risk, to guide data analysis. We use assessment data from a center paid to assess the inventions' economic potential. Inventors' choices whether to commercialize their inventions and later whether to remain in production were consistent with profit-seeking motives and risk aversion.
\end{abstract}

Keywords: Innovation, Invention, Entrepreneurship, Rationality, Risk, Entry, Exit, Survival, Sunk Cost

JEL Codes: M13, L11, O31

\section{Introduction}

The present paper is the first to use direct measures of market potential for inventions to assess two primary features of rational economic models, profit-seeking and risk aversion, among inventor-entrepreneurs. As elucidated by for example Jewkes, Sawers, and Stillerman (1959) and Baumol (1968), the most important inventions have stemmed most often from individual inventors and from autonomous individuals at institutions including universities. So there is good reason to care about the motivations and successes of entrepreneurs, and particularly of independent inventors.

While a growing theoretical literature addresses the optimal behavior of entrepreneurs and inventors, direct empirical measures of entrepreneurial opportunities and resulting behavior have been lacking. Several studies use indirect empirical tests and find aggregate evidence of 
profit seeking behavior, but without direct measures of characteristics of entrepreneurs' business opportunities (Bernhardt, 1994; Shane, 2001; Friedman and Silberman, 2003; Lach and Schankerman, 2004; Link and Siegel, 2005).

In addition, some recent studies seem to show economically nonsensical behavior by entrepreneurs. It has been found that a majority of people who enter entrepreneurship (75\%) are better off staying employed (Bernhardt 1994; Hamilton 2000), that entrepreneurs invest too much in their own businesses considering the risk and return (Moskowitz and VissingJorgensen, 2002), and that entrepreneurs expect better financial outcomes than employed persons but experience worse realizations (Arabsheibani et al., 2000). Furthermore, 97\% of inventors are better off not inventing (Åstebro, 2003) and a considerable fraction continues investing money in their inventions after being credibly informed that the invention has no economic value (Åstebro, Jeffrey and Adomdza, 2007). Inventors credibly advised that it is not worthwhile to commercialize their inventions sometimes did so anyway, with optimists spending 166\% more than pessimists (Åstebro, 2003; Åstebro, Jeffrey and Adomdza, 2007). Such nonsensical behavior is particularly troubling given the importance of inventorentrepreneurs to the economy. To explain these aberrations, economists assume that entrepreneurs are wishful thinkers (e.g., de Meza 2002), risk-seekers (e.g., Kihlstrom and Laffont, 1979; Kanbur, 1979), largely motivated by non-pecuniary benefits (Blanchflower and Oswald, 1998; Hamilton, 2000; Benz and Frey, 2008; Baumol, 2006), or "skewness lovers" (Åstebro, 2003). Indeed, experiments show that excess entry of entrepreneurs documented for example by Hamilton (2000) and Åstebro (2003) apparently arises from several decisionmaking biases such as overconfidence and optimism (Camerer and Lovallo, 1999; Coelho, de Meza and Reyniers, 2004; Hoelzl and Rustichini, 2005; Moore and Cain, 2007). Should such 
biases and non-pecuniary motivations be pervasive, policies to encourage innovation may be ineffective or even misguided. For example, there would be no reason to encourage entry if there is widespread overoptimism (de Meza, 2002). From a policy perspective it is therefore important to establish whether entrepreneurs, and especially independent inventors, respond sensibly to economic motives, or if their behavior is dominated by overconfidence, pleasure in risk, optimism, or (Baumol, 2006) the second currency of joy in the task of invention. This is our starting point for this paper.

To probe whether inventor-entrepreneurs' decisions match two central tenets of rational economic models, profit-seeking and risk aversion, this paper uses direct measures not only of individual inventors' decisions but also, for the first time, of economic characteristics of their business opportunities. The data are professional a priori assessments by an independent agency charging a substantial fee for the assessment. Two limitations of the data are that they involve rankings rather than exact numerical values, and that they are representative only of the subset of independent inventors who paid the Canadian Innovation Center (CIC) to review the prospects for their inventions and to advise on commercialization. These limitations notwithstanding, the measures seem a satisfactory means to move forward given that previous studies have used only indirect measures (and had other data limitations and subpopulations).

The data pertain only to independent inventors, who are not subject to established firms' institutional decision-making biases (cf., Henderson, 1993). The data further pertain to ideas at an early stage of development for which there remain significant development and commercialization decisions and efforts. Inventors who chose not to use the CIC's services predominantly did so, CIC analyses indicate, because they decided their inventions were of insufficient quality to motivate the assessment fee suggesting that our sample is truncated from 
below. Extremely optimistic or overconfident inventors or those with clear opportunities as well likely would not use the service as it would have no impact on their decision-making. We followed up these data to assess, for one thousand and twelve inventors, entry and exit from commercial production.

To guide the empirical analysis, we use a rational profit-seeking model involving uncertainty. Our model assumes that inventors respond to expected profitability of market opportunities, including sunk costs of entry and uncertainty. Sensitivity to uncertainty gauges whether entrepreneurs are risk-averse or risk-seeking.

We find that pecuniary incentives alter inventors' entry (commercialization) and exit (cessation of sales) decisions. The probability of entry rises significantly with greater expected sales, and falls significantly with greater expected manufacturing costs, competition from imitators, and development uncertainty. For exit, the estimated coefficients, while mostly statistically insignificant for theoretical and statistical power reasons, are likewise consistent with profit-seeking decisions. The entry and exit decisions observed are inconsistent with riskseeking behavior and with overconfidence that makes inventors expect high returns in highuncertainty situations, and are consistent with risk aversion. Entrepreneurial entry and exit seemingly can be explained, at least in part, by profit-seeking and risk-averse behavior.

\section{Model and Hypotheses}

We present a simple empirically-relevant model embodying the most obvious economic components - those for which we have data - of an inventor's investment decision. The model pertains to inventors (and their financiers) who face a decision whether to invest in bringing an invention to market, and then whether to remain in production or exit the market. The model 
allows for differences in inventors and their inventions, and for unpredictability in the development process and in the eventual markets for inventions.

The model is kept tractable by two key simplifying assumptions. Dynamics over time after entry, as in models such as Jovanovic (1982), are not formally analyzed. Instead we model market conditions as constant. Uncertainty is modeled through two representative variables - the ones for which we have measures. The portrayal of sunk cost and market size as random allows us to explore effects of randomness at both development and production stages.

\subsection{Model}

An inventor $i$ can pay sunk cost $S_{i}$ to commercialize an invention. Absent competition, the inventor then charges price $p_{i}$, pays fixed cost flow $F_{i}$ per year plus average variable production cost $c_{i}$, and produces and sells $Q_{i}$ units per year. In practice competition lessens the inventor's profit, relative to monopoly profit, by $\kappa_{i} \cdot{ }^{1}$ The resulting contemporaneous profit flow is $\pi_{i}=\left(p_{i}-c_{i}\right) Q_{i}-F_{i}-\kappa_{i}$, and continues from time 0 for $T_{i}$ years. Using discount rate $\rho_{i}$, a non-exiting inventor's discounted profit is therefore

$$
\Pi_{i}=\int_{0}^{T_{i}} e^{-\rho_{i} t} \pi_{i} d t-S_{i}=\pi_{i} \tilde{T}_{i}-S_{i},
$$

where $\tilde{T}_{i}=\frac{1}{\rho_{i}}\left(1-e^{-\rho_{i} T_{i}}\right)$.

Both product development and market outcomes are in part unpredictable. Their unpredictability is embodied by assuming that $S_{i}$ and $Q_{i}$ are independent random variables. $S_{i}$ and $Q_{i}$ have means $\mu_{i}$ and $v_{i}$, and standard deviations $\xi_{i}$ and $\psi_{i}$, respectively. The inventor knows in advance the distributions of $S_{i}$ and $Q_{i}$, but observes actual outcomes only after time 0 once sunk costs have been incurred and production has begun. 
Before and after entry, alternative opportunities are available to the inventor. Before entry, the best alternative life decision would yield the utility of a monetary payoff $\Omega_{i}>0$. After entry, the inventor can choose to exit when the inventor has finally ascertained $Q_{i}$, and thereafter until $T_{i}$ receive alternate revenue flow $\omega_{i}$ (or equivalent contributions to utility). After entry, therefore, production continues if and only if $\pi_{i}>\omega_{i}{ }^{2}$ Likewise, the inventor either pays for the sunk costs of product and market development, or takes the outside opportunity, whichever yields greater expected utility.

Non-restrictive technical assumptions are documented in an Appendix.

\subsection{Implications}

The model yields testable implications for inventors' decisions. Although some implications are obvious theoretically, all are important in assessing inventor responses to pecuniary motives and to risk. Mathematical proofs are in a separate paper available from the authors (Simons, 2009). The implications are labeled here as propositions P1-P9.

Four initial implications embody how inventors' entry decisions respond to profit opportunities. Expected sunk cost, manufacturing cost, and competition inhibit entry, while the demand characteristics of price and market size encourage entry:

P1. Greater expected sunk cost is associated with reduced probability of entry.

P2. Greater manufacturing cost (fixed and per unit) is associated with reduced probability of entry.

P3. Greater competition is associated with reduced probability of entry.

P4. Greater price and expected output are associated with increased probability of entry. These invention characteristics are not all that affects entry, for uncertainty plays a related role. 
Product development uncertainty and demand uncertainty affect expenditure and profit at the respective stages of development and production, but both affect inventors' decisions about entry. Risk-neutral inventors do not pander to uncertainty, but risk-averse or risk-seeking inventors alter their behavior according to the degree of uncertainty. ${ }^{3}$ With high uncertainty, risk-averse inventors fear low returns, and enter only if the potential profit is relatively high. With low uncertainty, risk-averse inventors have little fear of unpredictable returns, and enter even if the potential profit is lower. These responses to uncertainty are opposite for risk-seeking inventors: with high risk they seize the opportunity of high gains and enter even if they have low likely profit. Thus self-selection affects entry according to the amount of risk.

This is just half the story for demand uncertainty, because if the market turns out to be bad then the inventor exits and pursues an outside opportunity. High risk makes available high gains, while high losses are effaced by the option to exit. In contrast, the high risk of sunk development cost is not effaced by outside opportunity, since inventors do not know development costs until development is complete and continue development until they enter. ${ }^{4}$

Hence inventors' response to risk depends on whether the inventors are risk-averse or risk-seeking, and whether the risk pertains to a sunk cost versus a post-entry activity from which they can exit:

P5. If inventors are risk-averse (risk-seeking), greater development uncertainty is associated with reduced (increased) probability of entry.

P6. If inventors are risk-averse, greater demand uncertainty may decrease or increase the probability of entry. If inventors are risk-seeking, greater demand uncertainty unambiguously increases the probability of entry.

Inventors' self-selection for entry on the basis of risk and sunk cost has ramifications for exit. 
Unambiguous ramifications for exit arise only for sunk cost and associated risk. Expected sunk cost reduces expected utility, so an inventor with greater expected sunk cost requires a better opportunity in other ways to have sufficient expected utility to enter. After entering and paying the sunk cost, only the other benefits of the opportunity affect profit. Selfselection thus ensures that inventors with higher expected sunk cost are less likely to exit once they are producing their innovations:

P7. Greater expected sunk cost is associated with reduced probability and rate of exit. ${ }^{5}$

Risk in sunk cost has a similar effect to expected sunk cost, for identical reasons. Risk-averse inventors facing high uncertainty enter only if the opportunity is better in other ways, yielding a lower probability of exit among those inventors who enter. Risk-seeking inventors self-select in reverse. Hence:

P8. If inventors are risk-averse (risk-seeking), greater development uncertainty is associated with reduced (increased) probability and rate of exit.

Only for these two variables is the effect on exit unambiguous.

For other variables, the most that can be said is that typically worse values ought to have a nonnegative but near zero effect on exit. The effect is near zero; this is partly because a worse value reduces profit and so increases the probability of exit, but also means that the inventor had reasonably good values of other traits in order to enter and so decreases the probability of exit, with the former effect typically larger. (Demand uncertainty has especially complex effects and is not addressed.) Hence:

P9. Greater manufacturing cost (fixed and per unit) and competition most likely have nonnegative (but near zero) effects on the probability and rate of exit, while greater price 
and expected output most likely have nonpositive (but near zero) effects on the probability and rate of exit.

These tendencies are likely to hold for plausible distributions of inventor characteristics.

\subsection{Comparing Possible Modes of Inventor Behavior}

The model can help guide distinctive tests between some alternative theories. First, inventors' response to risk, in $\mathrm{P} 6$, differs depending on whether inventors are predominantly risk-averse or risk-seeking. Second, overconfidence is often defined as leading inventors to expect high returns in high-uncertainty situations. If inventors have full information except regarding project development costs and outcomes, overconfidence in high-uncertainty situations implies behavior analogous to risk-seeking, and hence evidence of risk-aversion implies that this form of overconfidence is not predominant in inventor behavior. Note however that another form of overconfidence, imperfect information about own abilities, is not testable here (it implies excess entry and exit regardless of the level of uncertainty, thus increasing the constant terms in models of entry and exit); similarly, inventor motivation by joy in the task of invention is not testable here. Third, the view that psychology but not economics drive inventor behavior implies that characteristics of the profit opportunity do not affect inventors' entry and exit decisions. Findings of risk-averse, profit-seeking behavior therefore reject the risk-seeking first view, as well as the second and third views, as predominant modes of inventor behavior.

\section{Data on Inventions and Their Commercialization}

The Canadian Innovation Centre (CIC) in Waterloo, Canada runs what it calls the Inventor's Assistance Program (IAP). This program helps inventors, before significant R\&D expenditures are made, to evaluate an invention. The evaluation's purpose is to advise potential entrepreneurs on whether and how to continue efforts. ${ }^{6}$ The CIC started in 1976 at the 
University of Waterloo as part of its technology transfer office and formed a separate entity in 1981. The CIC was until 1999 a not-for-profit organization supported $50 \%$ by the Canadian government and $50 \%$ by service fees. Government support for the IAP dried up in 2000 and fees subsequently quadrupled from Canadian $\$ 250$ to $\$ 1,000$ to cover costs. The IAP assessed 11,000 inventions over the period 1976-1996, and in the late 1990s it experienced about 1,000 submissions per year from all provinces in Canada. With the increase in costs and the concomitant expansion of local "Industrial Technology Advisors" from a branch of Industry Canada, the submissions to CIC have dwindled and today the IAP assesses only a fraction of the inventions it assessed in its heyday.

Inventors who chose not to use the IAP predominantly did so, IAP analyses indicate, because they decided their inventions were of insufficient quality to motivate the assessment fee suggesting that our sample is truncated from below. Extremely optimistic or overconfident inventors or those with clear opportunities as well likely would not use the service as it would have no impact on their decision-making. Program evaluators assess a range of economic variables including potential market size, costs, competition, and risk. The evaluation results in a report containing the scores of the economic variables together with a cover page containing an overall recommendation whether the inventor should stop or continue development efforts. Åstebro, Jeffrey and Adomdza (2007) show that $71 \%$ of those recommended to stop, do stop spending more money, while $51 \%$ still continue spending time on their invention. Åstebro (2003) reports that $82 \%$ of those recommended to continue do continue. The IAP agreed to provide us with their prior assessments of inventions' economic traits for inventions reviewed between 1989 and 2001. As much as $30 \%$ of the assessments were from repeat inventors. We 
removed all but one assessment from repeat inventors as well some records with incomplete data and drew a random sample from the remaining frame.

We measured economic outcomes, including entry and exit from production, through two waves of telephone interviews. The first wave covered the 1989-1993 assessment period resulting in 1,091 responses, and the second wave covered the 1994-2001 assessment period resulting in 830 responses. The second survey wave included detailed questions on inventor characteristics. Responses were obtained from $68 \%$ of all inventors contacted in the two waves. Due to shredding of documents at the IAP we could only match 541 survey responses from the first wave and 471 responses from the second wave with assessment records yielding a total of 1,012 analyzable observations. To ensure sufficient statistical power given the rarity of successful commercialization, 33 of the 1,012 observations were included because newspaper clippings and other sources suggested the invention might have reached the market, and the survey confirmed this conclusion. We use an econometric technique that corrects for this oversampling on the dependent variable (Manski and Lerman, 1977).

Precise dates of entry and exit (month and year) were recorded for commercialized inventions. Entry was defined as the start of sales of a product embodying an invention. Among the 101 inventions that reached commercial entry, 24 were soon licensed or otherwise used as revenue sources for generally modest sums with the inventor leaving the market, while the remaining 77 inventions had market survival times equal to the exit date minus entry date. We analyze exit times among the 77 remaining inventions. Exit times are treated as right-censored if exit had not occurred by the sampling date.

The evaluations of economic variables by the IAP were based on a well-established assessment process. Because assessments occurred before commercialization, ${ }^{7}$ they avoid 
problems pointed out in the psychological literature such as methods bias (Campbell and Fiske, 1959) and hindsight bias (Fischhoff, 1975). The measures take values of $-1,0$, or 1, and we treat the measures as cardinal, since experimentation with an ordinal (categorical) treatment yielded similar (and insignificantly different) results and since the cardinal treatment provides a straightforward summary of findings. The assessment process used a standardized preexisting method, which Baker and Albaum (1986) in a study of 86 judges and six products found to yield Cronbach (1951) alphas of 0.84 to 0.96 , implying highly comparable overall ratings across IAP personnel. The IAP's evaluators were extensively trained by a chief evaluator, who ran the program consistently from 1981 through 2000, and a group meeting at the end of each review provided feedback to ensure appropriate measures for each invention. The IAP's evaluations were found, in Åstebro's (2003) study of final ratings of the first survey wave, to successfully predict revenues of commercialized inventions.

Table 1 reports the measures and their precise descriptions, sources, and numbers of observations. Three of the measures, size of investment, tooling costs, and development uncertainty, were specifically assessed in ways that pertain only to sunk costs. In terms of the model, they pertain during the entry phase when the sunk cost is paid. The remaining measures, demand uncertainty, potential sales, manufacturing cost, and potential for competition from imitators, all pertain only to the period after entry. For the model's concept of sunk costs we use two measures: the size of investment and the cost of tooling. For the model's concepts of price and (expected) quantity, we use potential sales, which assesses the monetary value of sales and hence is a consequence of both price and quantity. For the model's concepts of fixed and variable costs, we use the single available manufacturing cost measure. 


\section{Empirical Evidence}

\subsection{The Inventors and Their Inventions}

The inventors and inventions in our sample are typical of serious independent inventors. Inventors' characteristics can be assessed using data on 471 of our 1,012 inventors, those that the IAP assessed in 1994-2001, since relevant questions were added in our second survey wave. The inventors' characteristics are summarized in Table 2. The inventors averaged 28 years' work experience and 9 years' business ownership experience. A majority, 53\%, had been business managers, $64 \%$ had been business owners, 34\% had owned at least two (up to ten) businesses, and 58\% had siblings or parents who had owned their own business. Their education was slightly higher than average for people of their ages, with $88 \%$ having a high school degree, $42 \%$ having graduated from a four-year university, and 10\% having one or more graduate degrees. They had often worked in multiple occupations, consistent with Lazear (2004): 73\% had worked in at least three occupations, and 33\% in at least six occupations. They averaged eight years' inventive experience; only for $26 \%$ was the invention their first, $17 \%$ had at least ten total inventions, and $1.3 \%$ claimed hundreds or thousands of inventions. A plurality of their inventions was consumer-oriented (47\%), including inventions for household and general consumer use (28\%) and sports and leisure applications $(15 \%)$.

The IAP's assessments of the inventions, along with the entry outcome, are described in Table 3. The table reports means, standard deviations, and correlations for each variable. Entry is 1 if an invention was commercialized or 0 if not. Among all inventors in the sample, 101 $(10.0 \%)$ entered (commercialized their products). The base rate of entry is estimated by excluding the deliberately oversampled observations, yielding a figure of $6.9 \%$. The economic assessments mostly have means near zero, indicating borderline ratings of potential by the IAP. 
Potential sales has a mean of -0.40 , indicating that most inventions were rated as having weak opportunities for sales. A substantial fraction, $29 \%$, of inventions were expected to face large R\&D expenditures, while only $3 \%$ were expected to have large sales volume, and these variables are somewhat skew distributed. Other variables are roughly centered around their means. Correlations between entry and the remaining variables are in the hypothesized directions, with the negative correlations between entry and development uncertainty, and between entry and demand uncertainty, suggestive of risk aversion on the part of inventors. The determinants of entry are better probed, however, in a multivariate analysis.

\subsection{Entry}

Inventions that were and were not commercialized are compared in Table 4. The table presents means and standard deviations of the economic traits for the 911 inventions that were not commercialized and the 101 inventions that were commercialized. Entrants on average had been rated to have lower investment and tooling costs, greater potential sales, lower manufacturing cost, less competition, and lower development uncertainty than non-entrants. The differences in mean traits, reported in the final column of Table 4, are all statistically significant. The only variable with a small and insignificant difference is demand uncertainty, consistent with the option to exit counteracting the dissuasion of demand risk.

To assess the joint determinants of commercial entry, we compute maximum likelihood estimates for the logistic regression model. The estimates are adjusted for oversampling on the dependent variable $Y$ using the method of prior correction (Manski and Lerman, 1977). This method yields consistent estimates regardless whether observations are sampled from the subpopulations in which $Y$ is 1 or 0 , or whether observations are randomly sampled from the full population and from one or both "choice based" subpopulations (a straightforward proof is King 
and Zeng's (2001) appendix B). The related econometric literature assumes investigators know the fraction of $1 \mathrm{~s}$ in the population of $Y$, as is pertinent for entirely choice based samples, but we estimate this fraction from our full-population segment of the sample. It can be shown readily that the estimates remain consistent, except possibly the standard errors which we estimate by the bootstrap method.

The estimated coefficients for ex ante assessments of economic costs and benefits are presented in Table 5. The full model estimates, in column (1) of the table, largely coincide with the model's characterization of profit-seeking and risk-averse inventor behavior. Potential sales has the largest estimated effect. An improvement from a rating of 0 to 1 in potential sales increases the estimated probability of entry, when other variables are at their means (as always below), from $6.8 \%$ to $14.1 \%$. Increased manufacturing cost or competition from imitators, again from 0 to 1 , decreases the estimated probability of entry from $5.0 \%$ to $2.8 \%$, or $5.0 \%$ to $3.5 \%$, respectively. Development uncertainty deters entry, consistent with risk aversion on the part of inventors. Increased development uncertainty, from 0 to 1 , decreases the estimated probability of entry from $5.1 \%$ to $2.8 \%$. Demand uncertainty's estimated coefficient has the opposite sign from development uncertainty and is near zero, consistent with the option to exit enhancing the expected benefits of demand risk. Potential sales, manufacturing cost, competition, and development uncertainty all have estimated effects that are statistically significant. Size of investment and tooling cost have coefficient estimates closer to zero and statistically insignificant; limited statistical power makes it difficult to know whether their effects are negative as pecuniary motives imply. The two sunk cost measures are the most highly correlated independent variables, and we report estimates in columns (2) and (3) with only one of these measures at a time. In both cases the measures have negative coefficient estimates, fairly near 
zero relative to their standard errors, and other coefficient estimates change little. Controlling for changes in Canadian gross domestic product (GDP), from two years in the past to two years in the future, has little effect on the estimates as shown in column (4). To the extent there is sufficient statistical power to put clear signs on the estimates, the findings universally confirm the hypothesized patterns for profit-seeking risk-averse inventors. ${ }^{8}$

\subsection{Exit}

We probe the causes of exit despite at least four reasons why the true effects of economic characteristics should be difficult to observe among rational profit-seeking inventors: forecasts versus realizations, self-selected measurement errors, statistical leverage reduction, and sample size. Forecasts by inventors and their financiers are the only information they have to decide whether to enter, while realized values that are notoriously hard to predict ultimately determine profitability and hence exit, so a priori economic measures should influence entry more than exit. Measurement errors in a priori assessments are compounded by self-selection to enter, because inventions independently assessed as having poor prospects will only be commercialized if the assessments were wrong and the true prospects (as assessed by the inventors) meet at least the minimum standard of commercialized inventions; this biases coefficients toward zero (simulations show that mismeasurement of a single variable might easily bias its coefficient estimates downward by a factor of four while other coefficient estimates fall by a factor of two). Statistical leverage, the variability in independent variables that facilitates estimation, falls as self-selection weeds out unattractive values of the independent variables, increasing standard errors (by, simulations suggest, about $10 \%$ to $30 \%$ ). Sample size severely limits statistical power because only 77 of the 1,012 inventions were commercialized and have useable data on survival 
times; this reduction in sample size increases standard errors (by roughly a multiple of $\sqrt{1012 / 77}=3.6)$.

Despite these biases toward zero and losses of statistical power, it is interesting to probe for signs of pecuniary motives in the exit patterns. Causes of exit were probed using statistical survival analysis with, alternatively, the exponential and Weibull models. ${ }^{9}$ The Weibull model allows for a time-varying exit probability. The exit time for inventors still producing at the time of data collection is treated as right-censored.

Maximum likelihood estimates of both models are shown in Table 6. The variables are equally scaled with comparable standard deviations, so the magnitudes of the coefficients speak directly to their relative importance. Nearly identical estimates result regardless which survival function is imposed, and virtually the same results arise using other common formulae or Cox's nonparametric model. ${ }^{10}$ Correcting for right censoring the estimated mean probability of exit is 0.10 per year, implying an average survival time of 10 years.

The estimates concur with the profit-seeking and risk-averse economic model. Expected competition triples the estimated yearly exit rate if the competition measure rises from 0 to 1 , and is the only statistically significant variable. The evidence provides modest further empirical support for pecuniary motives in inventor behavior.

\subsection{Reasons for Entry and Exit}

To further probe inventors' decisions, we collected responses stating why inventors did not enter or why they exited the market. Responses for entry decisions are available only for inventors who did not enter, and responses for exit decisions are available only for inventors who exited by the time of survey. Respondents could state multiple reasons. The data provide a 
secondary means to assess how often profit-driven behavior causes entry and exit and to confirm the earlier estimation results.

In Table 7, the top panel reports the percentage of inventors who stated each reason for choosing not to enter. The most common reason was that the IAP recommended that the inventor abandon further efforts (42\%), confirming that inventors took the IAP's assessments seriously. Lack of capital made up $32 \%$ of reasons, a pre-existing similar product $22 \%$, continuing development $18 \%$, followed by many other reasons around or below $10 \%$. Among the non-pecuniary reasons it is notable that $27 \%$ of the inventors abandoned their efforts because, they indicated, they lacked knowledge on how to commercialize their invention. The few other non-pecuniary reasons were less frequent, below $10 \%$.

We further analyzed reasons for non-entry stratified by the IAP's summary recommendations to stop versus go forward with commercialization, indicated in Table 7 by the headings Stop and Go. The distribution of reasons was similar in the two cases, but some differences arose. Lack of capital was a more frequent problem for those recommended to go forward (39\%) versus those recommended to stop (30\%), a difference significant at the .01 level using Fisher's exact test, possibly signaling capital market failures. The lack of a buyer for intellectual property was blamed for non-entry in $14 \%$ of cases among inventions recommended by the IAP compared to only $7 \%$ among inventions not recommended by the IAP, a difference significant at the .01 level. Inventors recommended to go ahead with commercialization more often (7\% versus $4 \%)$ discontinued their activities because of better opportunities elsewhere (difference significant at the .06 level), suggesting that inventor ability yields work opportunities. Among the non-pecuniary reasons an unwillingness to commercialize was more common for inventors recommended to go ahead (10\%) versus stop (5\%) (difference significant at the .07 
level). All such differences may have arisen endogenously; for example, reported difficulties finding capital and selling intellectual property may have arisen because inventors of higherrated inventions more actively searched for capital and buyers of intellectual property.

The bottom panel similarly catalogues reasons for exit. The dominant reason associated with exit was low sales volume (31\%), followed by lack of capital (23\%) and high opportunity costs (14\%). The two most frequent non-pecuniary reasons for exit are family or personal reasons (12\%) and loss of interest (also 12\%). Hence, again, pecuniary motives seem to dominate inventors' decision making.

\section{Conclusion}

Our theory and empirical results address a current debate regarding whether entrepreneurs are economically rational. Accumulating evidence suggests that there is excess entrepreneurial entry and that this excess entry is driven by non-pecuniary considerations such as greater autonomy, broader skill utilization, and the possibility to pursue one's own ideas (Åstebro and Thompson, 2007; Benz and Frey, 2008; Benz, 2009). If pervasive, such evidence may question the use of policies to encourage investment in innovation by inventors. We extend the study of entrepreneurial decisions to both entry and exit, characterize how both would be influenced rationally by pecuniary motives, and investigate how entrepreneurs actually respond to financial characteristics of real inventions. The findings do not rule out imperfect rationality and non-financial motives on the part of entrepreneurs. However, the findings confirm that profit-seeking motives and risk aversion substantially drive the entry decisions, and perhaps also exit decisions, of inventor-entrepreneurs.

These findings do not rule out irrationality on the part of inventors. Indeed, Åstebro, Jeffrey, and Adomdza (2007) confirm significant effects of optimism in entry decisions in a 
subgroup of the inventors studied here. However, pecuniary variables and risk seem to have effects independent of these psychological traits. Hence our findings are consistent with previous literature showing decision making biases among entrepreneurs. Our evidence does imply, however, that overconfidence in high-risk situations is not a predominant behavior. While some biases and aberrations to profit-seeking behavior indeed affect the decision to commercialize inventions, economics (risk aversion and the search for profit) apparently still matter when it comes to commercializing inventions.

The evidence confirms that positive monetary incentives should enhance commercialization of inventions, although current evidence is insufficient to draw more detailed policy implications. Motivating inventors to invent by for example tax write-offs or direct grants to research may be socially optimal, but the level at which these incentives should be provided is unclear. Studies have not yet analyzed social welfare effects of decision-making biases in innovation. It is clear from Åstebro (2003) that the average entering inventor may not be better off and that the extra entrants tend to be of lower quality with such incentives, but society as a whole may still benefit. Inventors do respond to economic incentives, which is comforting news for policy makers.

\section{Appendix: Technical Assumptions of the Model}

The model focuses on inventors for whom the price-cost margin is positive, $p_{i}-c_{i}>0$, given their choice of output, since inventors with $p_{i}-c_{i} \leq 0$ would have $\Pi_{i}<0$ and hence would never commercialize their inventions (and have no effect on the propositions derived from the model). It is assumed that $T_{i}, \rho_{i}, p_{i}, c_{i}, Q_{i}, F_{i}, S_{i}>0$. 
The probability density functions (p.d.f.s) of $S_{i}$ and $Q_{i}$ are $f_{i}^{S}\left(S_{i}\right)$ and $f_{i}^{Q}\left(Q_{i}\right)$ respectively. The p.d.f.s may be quite general, as they need only be bounded and satisfy the usual first and second order dominance conditions in appropriate parameters. $S_{i}$ and $Q_{i}$ respectively are increasing in their means $\mu_{i}$ and $v_{i}$, in the sense of first order stochastic dominance, and increasing in risk in their standard deviations $\xi_{i}$ and $\psi_{i}$, in the sense of second order stochastic dominance. This allows for example for skew distributions of $S_{i}$ and $Q_{i}{ }^{11}$

The time when the inventor has finally ascertained $Q_{i}$ is denoted $t_{i}^{x}$, and is defined such that $\alpha_{i}\left(0<\alpha_{i}<1\right)$ is the fraction of the discounted profit flow up to this time. The alternate revenue flow $\omega_{i}$ (or equivalent contributions to utility) is defined such that it yields discounted value $\beta_{i} \Omega_{i}\left(0 \leq \beta_{i} \leq 1-\alpha_{i}\right){ }^{12,13}$ Inventor $i$ 's utility function is denoted as $U_{i}(\cdot)$, which is strictly increasing, differentiable, and bounded. The inventor therefore enters if and only if

$$
\begin{aligned}
\operatorname{Pr} & {\left[\pi_{i}>\omega_{i}\right] E\left[U_{i}\left(\Pi_{i} \mid \pi_{i}>\omega_{i}\right)\right] } \\
& +\operatorname{Pr}\left[\pi_{i} \leq \omega_{i}\right] E\left[U_{i}\left(\alpha_{i} \pi_{i} \tilde{T}_{i}+\beta_{i} \Omega_{i}-S_{i} \mid \pi_{i} \leq \omega_{i}\right)\right]>U_{i}\left(\Omega_{i}\right) .
\end{aligned}
$$

The inventor thus considers the opportunity for exit in determining whether to enter.

Outcomes in the population of inventors depend on the distribution of traits. Let $\theta_{i}=\left(p_{i}, c_{i}, F_{i}, \kappa_{i}, \mu_{i}, v_{i}, \xi_{i}, \psi_{i}, \rho_{i}, \tilde{T}_{i}, \alpha_{i}, \beta_{i}, \Omega_{i}, f_{i}^{S}(\cdot), f_{i}^{Q}(\cdot), U_{i}(\cdot)\right)$ denote the parameter vector for each inventor. ${ }^{14}$ The parameter space is assumed to be convex, and non-degenerate in that even given certain data-driven parameter values all entry and exit outcomes are possible. ${ }^{15}$ The distributions of $\rho_{i}, \tilde{T}_{i}$, and $\alpha_{i}$ are assumed to yield a finite probability density function for $t_{i}^{x}$ at all times $t_{i}^{x} \in\left(0, \max \left(T_{i}\right)\right)$, where $\max \left(T_{i}\right)$ is the maximum possible value of $T_{i}=-\ln \left(1-\rho_{i} \tilde{T}_{i}\right) / \rho_{i}$. The parameter vector is assumed to be independently and identically 
distributed (i.i.d.) across inventors. ${ }^{16}$ Parameters $p_{i}, c_{i}, F_{i}, \kappa_{i}, \mu_{i}, v_{i}, \xi_{i}$, and $\psi_{i}$ are assumed to be distributed independently (or in practice they could be analyzed using proper controls in statistical analyses). Parameters $\rho_{i}, \tilde{T}_{i}$, and $\alpha_{i}$ are assumed to be (jointly) distributed independently of other parameters.

\section{Notes}

${ }^{1}$ Our results extend to very general functional forms robust to alternative competitive models. The term $\kappa_{i}$ in the profit equation can be replaced with a differentiable function $K_{i}\left(\kappa_{i} ; p_{i}, c_{i}, Q_{i}, F_{i}\right)$, where $\kappa_{i}$ is again an index of competition (reflecting the number and nature of competitors) and $\frac{\partial K_{i}}{\partial \kappa_{i}}>0$. As long as increases in $p_{i}$ or $Q_{i}\left(c_{i}\right.$ or $\left.F_{i}\right)$ yield smaller marginal competitive losses (gains) than the marginal benefits (losses) in the term $\left(p_{i}-c_{i}\right) Q_{i}-F_{i}$, our conclusions remain unaltered. This includes, for example, cases in which revenues, or positive profits, are divided by the index $\kappa_{i}$. Our conclusions extend even beyond this generalization as long as an appropriate weighted average of different inventors' competitive losses (gains) exceed the corresponding weighted average of benefits (losses) in the term $\left(p_{i}-c_{i}\right) Q_{i}-F_{i}$.

${ }^{2}$ Hopenhayn and Vereshchagina (2009), among many others, nicely analyze the role of outside opportunities in entrepreneurs' entry decisions.

${ }^{3}$ The hypotheses developed here assume all (or most) inventors are of one type. If inventors have mixed risk preferences, the result is in between the predicted outcomes.

${ }^{4}$ In a more general dynamic model where remaining development cost estimates are revised during the development process, the fact that actual remaining development costs decrease as 
more $R \& D$ is completed would tend to inhibit exit during development, maintaining the distinction derived here between development uncertainty versus demand uncertainty.

${ }^{5}$ Rate of exit, which is a function of time since entry, is the probability of exit per unit of time for a randomly-selected inventor who has entered but not yet exited. The definition is identical to that used in statistical survival analysis.

${ }^{6}$ For further descriptions see Udell (1989), Udell et al. (1993), and Åstebro and Gerchak (2001).

${ }^{7}$ Average time between evaluation and market launch was approximately two years (Åstebro, 2003). R\&D expenses for inventions that later reached the market averaged Cdn. $\$ 255,370$, but R\&D expenses for the same inventions up to the date of evaluation had averaged only Cdn. $\$ 87,850$ (2003 values).

${ }^{8}$ These results appear to be robust to a range of controls for inventor ability and psychological characteristics. Data on inventor ability and psychological characteristics are available for the subset of the data collected in our second survey wave, and we re-estimated the entry models using this subset of the data with and without controls for ability and psychological characteristics. Although standard errors are substantially larger given the limited sample size, it is informative that the point estimates for our pecuniary and risk variables changed little between models with and without these controls, using the same observations each time. With controls for managerial experience, log (one plus) years of business ownership experience, log (one plus) number of businesses owned, whether other family members operated a business, log (one plus) years of work experience, log number of occupational fields of experience, high school education, college education, graduate education, log (one plus) number of degrees, log (one plus) years of inventive experience, and log number of inventions, or various subsets of these variables, the point estimates changed fairly little (diminishing $49 \%$ for tooling cost, at most $31 \%$ 
for other estimates, and on average 26\%). With controls for optimism, overconfidence, risk aversion, and enjoyment of inventing, the point estimates changed even less (diminishing at most $17 \%$ and on average $4 \%$ ). With both sets of controls used simultaneously, changes in point estimates were also limited (diminishing $58 \%$ for tooling cost, at most $46 \%$ for other estimates, and on average $23 \%$ ). In each model, the full set of variables is highly jointly statistically significant, as are the economic (pecuniary and risk) variables as a set, and as are the inventor abilities as a set. The psychological variables in contrast are never jointly significant at the $p<.10$ level. In all cases, although the large standard errors make almost all estimates statistically insignificant, the estimates had the same signs as those presented in Table 5.

${ }^{9}$ The hazard of exit for a surviving business is $\lambda_{i}=\exp \left(\alpha+\beta^{\prime} X_{i}\right)$ in the exponential model or $\lambda_{i}=p t^{p-1} \exp \left(\alpha+\beta^{\prime} X_{i}\right)$ in the Weibull model.

10 The estimate of the time-related parameter, $\ln (p)$, in the Weibull model implies that the probability of exit falls from 0.087 in the first year to 0.065 in the eighth year, for a commercialized invention with mean characteristics.

11 A special case is $S_{i}=\mu_{i}+\xi_{i} \varepsilon_{i}^{S}, Q_{i}=v_{i}+\psi_{i} \varepsilon_{i}^{Q}$, where $\varepsilon_{i}^{S}$ and $\varepsilon_{i}^{Q}$ may be any continuous (possibly skew) independent random variables (whose distributions may differ for each $i$ ).

${ }^{12}$ It is in the inventor's interest to choose the earliest possible exit time $t_{i}^{x}$ (the smallest possible $\alpha_{i}$ ) after $S_{i}$ and $Q_{i}$ are realized, but knowledge of the value of $Q_{i}$ is typically substantially delayed after commercial production of a product begins.

${ }^{13}$ This implies $t_{i}^{x}=\frac{-\ln \left(1-\alpha_{i} \rho_{i} \tilde{T}_{i}\right)}{\rho_{i}}$ with $0<t_{i}^{x}<T_{i}$ and $\omega_{i}=\frac{\beta_{i} \Omega_{i}}{\left(1-\alpha_{i}\right) \tilde{T}_{i}}>0$. 
${ }^{14}$ We write the parameters $f_{i}^{S}(\cdot), f_{i}^{Q}(\cdot)$, and $U_{i}(\cdot)$, which are functions, as shorthand to mean one or more real-valued parameters yielding all possible variation in the functions. That is, write the general functions $f_{\text {all }}^{S}\left(\overrightarrow{\boldsymbol{f}}_{i}^{S}, \mu_{i}, \xi_{i}, z_{i}^{1}\right)=f_{i}^{S}\left(z_{i}^{1}\right), \quad f_{\text {all }}^{Q}\left(\overrightarrow{\boldsymbol{f}}_{i}^{Q}, v_{i}, \psi_{i}, z_{i}^{2}\right)=f_{i}^{Q}\left(z_{i}^{2}\right), \quad$ and $U_{\text {all }}\left(\overrightarrow{\boldsymbol{u}}_{i}, z_{i}^{3}\right)=U_{i}\left(z_{i}^{3}\right)$, and in $\theta_{i}$ the terms $f_{i}^{S}(\cdot), f_{i}^{Q}(\cdot)$, and $U_{i}(\cdot)$ are simplified notations for $\overrightarrow{\boldsymbol{f}}_{i}^{S}$, $\overrightarrow{\boldsymbol{f}}_{i}^{Q}$, and $\overrightarrow{\boldsymbol{u}}_{i}$ respectively. The number of elements in $\overrightarrow{\boldsymbol{f}}_{i}^{S}, \overrightarrow{\boldsymbol{f}}_{i}^{Q}$, and $\overrightarrow{\boldsymbol{u}}_{i}$ is assumed to be finite, and the general functions are assumed to be piecewise continuous in the elements of $\overrightarrow{\boldsymbol{f}}_{i}^{S}, \overrightarrow{\boldsymbol{f}}_{i}^{Q}$, and $\overrightarrow{\boldsymbol{u}}_{i}$.

${ }^{15}$ Specifically, the parameter vector has non-zero probability for the population of inventors in (and zero probability outside) a space that is assumed to be convex; to include for each $p_{i}, c_{i}$, $F_{i}, \kappa_{i}, \mu_{i}, v_{i}, \xi_{i}$, and $\psi_{i}$ values $\theta_{i}$ that lead (for a nonzero fraction of inventors) to each possible outcome non-entry, entry followed by exit, and entry without exit; and to include more than one possible value for each parameter.

${ }^{16}$ Random sampling ensures that collected data are i.i.d.

\section{References}

Arabsheibani, Gholamreza, David de Meza, John Maloney, and Bernard Pearson. 2000. “And a Vision Appeared Unto them of a Great Profit: Evidence of Self-Deception among the SelfEmployed." Economics Letters, 67(1), 35-41.

Åstebro, Thomas. 2003. "The Return to Independent Invention: Evidence of Risk Seeking, Extreme Optimism or Skewness-Loving?” Economic Journal, 113(484), 226-239.

Åstebro, Thomas, and Yigal Gerchak. 2001. "Profitable Advice: The Value of Information Provided by Canada's Inventor's Assistance Program." Economics of Innovation and New Technology, 10(1), 45-72. 
Åstebro, Thomas, Scott A. Jeffrey, and Gordon K. Adomdza. 2007. "Inventor Perseverance after Being Told to Quit: The Role of Cognitive Biases." Journal of Behavioral Decision Making, 20(3), 253-272.

Åstebro, Thomas, and Peter Thompson. 2007. "Entrepreneurs: Jacks of all Trades or Hobos?” University of Toronto Working Paper.

Baker, Kenneth G., and Gerald S. Albaum. 1986. "Modeling New Product Screening Decisions." Journal of Product Innovation Management, 3(1), 32-39.

Baumol, William J. 1968. "Entrepreneurship in Economic Theory." American Economic Review, $58(2), 64-71$.

Baumol, William J. 2006. "Return of the Invisible Men: The Microeconomic Value Theory of Inventors and Entrepreneurs." Paper presented at the annual meeting of the American Economic Association, Boston.

Benz, Matthias. 2009. "Entrepreneurship as a Non-Profit-Seeking Activity." International Entrepreneurship and Management Journal, 5(1), 23-44.

Benz, Matthias, and Bruno S. Frey. 2008. "Being Independent is a Great Thing: Subjective Evaluations of Self-Employment and Hierarchy." Economica, 75(298), 362-383.

Bernhardt, Irwin. 1994. "Comparative Advantage in Self-Employment and Paid Work." Canadian Journal of Economics, 27(2), 273-289.

Blanchflower, David G., and Andrew J. Oswald. 1998. "What Makes an Entrepreneur?” Journal of Labor Economics, 16(1), 26-60.

Camerer, Colin, and Dan Lovallo. 1999. "Overconfidence and Excess Entry: An Experimental Approach." American Economic Review, 89(1), 306-318. 
Campbell, Donald T., and Donald W. Fiske. 1959. "Convergent and Discriminant Validation by the Multi-Trait-Multi-Method Matrix.” Psychological Bulletin, 56(2), 81-105.

Coelho, Marta, David de Meza, and Diane Reyniers. 2004. "Irrational Exuberance, Entrepreneurial Finance, and Public Policy.” International Tax and Public Finance, 11(4), $391-417$.

Cronbach, Lee J. 1951. "Coefficient Alpha and the Internal Structure of Tests." Psychometrika, $16(3), 297-334$.

De Meza, David. 2002. “Overlending?” The Economic Journal, 112(477), F17-F31.

Fischhoff, Baruch. 1975. "Hindsight $\neq$ Foresight: The Effect of Outcome Knowledge on Judgment under Uncertainty." Journal of Experimental Psychology: Human Perception and Performance, 1(3), 288-299.

Friedman, Joseph, and Jonathan Silberman. 2003. "University Technology Transfer: Do Incentives, Management, and Location Matter?” Journal of Technology Transfer 28(1), 17-30.

Hamilton, Barton H. 2000. "Does Entrepreneurship Pay? An Empirical Analysis of the Returns to Self-Employment." Journal of Political Economy, 108(3), 604-631.

Henderson, Rebecca. 1993. "Underinvestment and Incompetence as Responses to Radical Innovation: Evidence from the Photolithographic Alignment Equipment Industry." RAND Journal of Economics, 24(2), 248-270.

Heston, Alan, Robert Summers, and Bettina Aten. 2006. Penn World Table Version 6.2, Center for International Comparisons of Production, Income and Prices at the University of Pennsylvania.

Hopenhayn, Hugo A., and Galina Vereshchagina. 2009. "Risk Taking by Entrepreneurs." American Economic Review, 99(5), 1808-1830. 
Hoelzl, Erik, and Aldo Rustichini. 2005. "Overconfident: Do You Put Your Money on It?" Economic Journal, 115(503), 305-318.

Jewkes, John, David Sawers, and Richard Stillerman. 1959. The Sources of Invention. New York: St. Martin's Press.

Jovanovic, Boyan. "Selection and the Evolution of Industry." 1982. Econometrica, 50(3), 649670.

Kanbur, S. M. 1979. "Of Risk Taking and the Personal Distribution of Income." Journal of Political Economy, 87(4), 769-797.

Kihlstrom, Richard E., and Jean-Jacques Laffont. 1979. “A General Equilibrium Entrepreneurial Theory of Firm Formation based on Risk Aversion." Journal of Political Economy, 87(4), 719-748.

King, Gary, and Langche Zeng. 2001. "Logistic Regression in Rare Events Data." Political Analysis, 9(2), 137-163.

Lach, Saul, and Mark Schankerman. 2004. "Royalty Sharing and Technology Licensing in Universities." Journal of the European Economic Association, 2(2-3), 252-264.

Lazear, Edward. 2004. "Balanced Skills and Entrepreneurship." American Economic Review, 94(2), 208-211.

Link, Albert, and Donald Siegel. 2005. "Generating Science-Based Growth: An Econometric Analysis of the Impact of Organizational Incentives on University-Industry Technology Transfer." European Journal of Finance, 11(3), 169-181.

Manski, Charles F., and Steven R. Lerman. 1977. "The Estimation of Choice Probabilities from Choice Based Samples." Econometrica, 45(8), 1977-1988. 
Moore, Don A., and Daylian M. Cain. 2007. "Overconfidence and Underconfidence: When and Why People Underestimate (and Overestimate) the Competition.” Organizational Behavior and Human Decision Processes, 103(2), 197-213.

Moskowitz, Tobias, and Annette Vissing-Jorgensen. 2002. “The Returns to Entrepreneurial Investment: A Private Equity Premium Puzzle?" American Economic Review, 92(4), 745-778.

Shane, Scott. 2001. "Technological Opportunities and New Firm Creation." Management Science, 47(2), 205-220.

Simons, Kenneth L. 2009. “A Theory of Entrepreneurial Behavior, Profit Opportunities, and Risks: Mathematical Derivations.” Manuscript.

Udell, Gerald G. 1989. "Invention Evaluation Services: A Review of the State of the Art." Journal of Product Innovation Management, 6(3), 157-168.

Udell, Gerald G., Ronald Bottin, and David D. Glass. 1993. "The Wal-Mart Innovation Network: An Experiment in Stimulating American Innovation." Journal of Product Innovation Management, 10(1), 23-34. 
Table 1. Variable Definitions, Sources of Data, Numbers of Observations

\begin{tabular}{|c|c|c|c|}
\hline Variable & Description & Source of Data & $\begin{array}{l}\text { Number of } \\
\text { Observations }\end{array}$ \\
\hline Entry & $\begin{array}{l}=1 \text { if sale of product } \\
\text { embodying invention, else } 0\end{array}$ & $\begin{array}{l}\text { First and second } \\
\text { survey }\end{array}$ & $1,091+830=1,921$ \\
\hline Survival Duration & $\begin{array}{l}\text { Months business continued } \\
\text { after product introduction } \\
\text { (right-censored values are } \\
\text { accounted for) }\end{array}$ & $\begin{array}{l}\text { First and second } \\
\text { survey }\end{array}$ & 77 \\
\hline Size of Investment & $\begin{array}{l}\text { Is the total investment } \\
\text { required for the project likely } \\
\text { to be obtainable? }\end{array}$ & IAP paper records & $\begin{array}{l}541+471= \\
1,012\end{array}$ \\
\hline Tooling Cost & $\begin{array}{l}\text { How great a burden is the } \\
\text { cost of production tooling } \\
\text { required to meet the } \\
\text { expected demand? }\end{array}$ & IAP paper records & $\begin{array}{l}541+471= \\
1,012\end{array}$ \\
\hline Potential Sales & $\begin{array}{l}\text { Is the sales volume for this } \\
\text { particular innovation likely to } \\
\text { be sufficient to justify } \\
\text { initiating the project? }\end{array}$ & IAP paper records & $\begin{array}{l}541+471= \\
1,012\end{array}$ \\
\hline $\begin{array}{l}\text { Manufacturing } \\
\text { Cost }\end{array}$ & $\begin{array}{l}\text { Does production at a } \\
\text { reasonable cost level appear } \\
\text { possible? }\end{array}$ & IAP paper records & $\begin{array}{l}541+471= \\
1,012\end{array}$ \\
\hline $\begin{array}{l}\text { Competition from } \\
\text { Imitators }\end{array}$ & $\begin{array}{l}\text { Is this innovation likely to } \\
\text { face new competition in the } \\
\text { marketplace from other } \\
\text { innovations that must be } \\
\text { expected to threaten its } \\
\text { market share? }\end{array}$ & IAP paper records & $\begin{array}{l}541+471= \\
1,012\end{array}$ \\
\hline $\begin{array}{l}\text { Development } \\
\text { Uncertainty }\end{array}$ & $\begin{array}{l}\text { What degree of uncertainty } \\
\text { is associated with complete } \\
\text { successful development from } \\
\text { the present condition of the } \\
\text { innovation to the market } \\
\text { ready state? }\end{array}$ & IAP paper records & $\begin{array}{l}541+471= \\
1,012\end{array}$ \\
\hline $\begin{array}{l}\text { Demand } \\
\text { Uncertainty }\end{array}$ & $\begin{array}{l}\text { How closely will it be } \\
\text { possible to predict sales? }\end{array}$ & IAP paper records & $\begin{array}{l}541+471= \\
1,012\end{array}$ \\
\hline $\begin{array}{l}\text { Inventor } \\
\text { Demographics }\end{array}$ & Various & Second survey & 830 \\
\hline $\begin{array}{l}\text { Canadian Gross } \\
\text { Domestic Product } \\
\text { (GDP) Changes }\end{array}$ & $\begin{array}{l}\text { Percentage annual growth in } \\
\text { GDP from previous year to } \\
\text { current year; also lags and } \\
\text { leads of these changes }\end{array}$ & $\begin{array}{l}\text { Heston, Summers, } \\
\text { and Aten (2006) }\end{array}$ & 1,012 \\
\hline
\end{tabular}


Table 2. Summary Statistics: Demographic Variables for Inventors and Matched Sample from General Population

\begin{tabular}{|c|c|c|c|}
\hline & Fract & ons & \\
\hline & Inventors & $\begin{array}{c}\text { General } \\
\text { Population }\end{array}$ & $\begin{array}{c}t \\
\text { statistic }\end{array}$ \\
\hline MALE & 0.91 & 0.91 & 0.00 \\
\hline MARRIED & 0.89 & 0.88 & 0.86 \\
\hline INCOME & & & \\
\hline$<\$ 30,000$ & 0.12 & 0.14 & -0.72 \\
\hline$\$ 30,000-\$ 50,000$ & 0.17 & 0.20 & -1.04 \\
\hline$\$ 50,000-\$ 70,000$ & 0.21 & 0.16 & 1.62 \\
\hline$\$ 70,000-\$ 100,000$ & 0.23 & 0.23 & 0.16 \\
\hline$>\$ 100,000$ & 0.28 & 0.27 & 0.25 \\
\hline AgE & & & \\
\hline$<35$ & 0.04 & 0.29 & -8.85 \\
\hline $35-44$ & 0.30 & 0.35 & -1.39 \\
\hline $45-54$ & 0.36 & 0.18 & 6.06 \\
\hline$\geq 55$ & 0.29 & 0.18 & 4.14 \\
\hline WORK EXPERIENCE & & & \\
\hline$<9$ years & 0.02 & 0.05 & -2.76 \\
\hline $10-19$ years & 0.13 & 0.13 & 0.14 \\
\hline$\geq 20$ years & 0.85 & 0.82 & 1.57 \\
\hline OCCUPATIONAL FIELDS & & & \\
\hline 1 & 0.11 & 0.16 & -2.28 \\
\hline 2 or 3 & 0.38 & 0.39 & -0.44 \\
\hline 4 or 5 & 0.26 & 0.28 & -0.77 \\
\hline$>5$ & 0.25 & 0.16 & 3.53 \\
\hline INDUSTRIES WORKED IN & & & \\
\hline 1 & 0.15 & 0.26 & -3.53 \\
\hline 2 or 3 & 0.40 & 0.41 & -0.38 \\
\hline 4 or 5 & 0.27 & 0.20 & 2.44 \\
\hline 6 to 10 & 0.12 & 0.10 & 1.06 \\
\hline$>10$ & 0.06 & 0.04 & 1.59 \\
\hline EDUCATION & & & \\
\hline Did not complete high school & 0.11 & 0.15 & -1.79 \\
\hline High school & 0.15 & 0.16 & -0.44 \\
\hline Trade school & 0.14 & 0.13 & 0.63 \\
\hline Some college & 0.16 & 0.18 & -0.70 \\
\hline College degree & 0.18 & 0.14 & 1.57 \\
\hline Professional degree & 0.15 & 0.09 & 2.78 \\
\hline Graduate studies & 0.11 & 0.15 & 1.76 \\
\hline Arts or social science & 0.51 & 0.45 & 1.04 \\
\hline Science or engineering & 0.34 & 0.29 & 0.99 \\
\hline Business degree & 0.16 & 0.20 & -0.89 \\
\hline BUSINESS BACKGROUND & & & \\
\hline Ever been self employed & 0.72 & 0.43 & 8.75 \\
\hline Ever owned a business & 0.67 & 0.43 & 7.31 \\
\hline No. of businesses owned & 1.49 & 0.69 & 7.12 \\
\hline Entrepreneurial family & 0.55 & 0.47 & 2.63 \\
\hline
\end{tabular}

Note.-Two-tailed $t$-test with unequal group variances for differences between inventor and general population samples. Reprinted with permission from Åstebro and Thompson (2007). 
Table 3. Sample Means, Standard Deviations, and Correlations for Key Variables

\begin{tabular}{|c|c|c|c|c|c|c|c|c|c|c|}
\hline \multirow[b]{2}{*}{ Variable } & \multirow[b]{2}{*}{ Mean } & \multirow[b]{2}{*}{$\begin{array}{l}\text { Std. } \\
\text { Dev. }\end{array}$} & \multicolumn{8}{|c|}{ Correlations } \\
\hline & & & Entry & $\begin{array}{l}\text { Size of } \\
\text { Investm. }\end{array}$ & $\begin{array}{l}\text { Tooling } \\
\text { Cost }\end{array}$ & $\begin{array}{l}\text { Potential } \\
\text { Sales }\end{array}$ & $\begin{array}{l}\text { Manuf. } \\
\text { Cost }\end{array}$ & $\begin{array}{l}\text { Comp. } \\
\text { Imitators }\end{array}$ & $\begin{aligned} & \text { Devel. } \\
& \text { S Uncert. }\end{aligned}$ & $\begin{array}{l}\text { Demand } \\
\text { Uncert. }\end{array}$ \\
\hline Entry & 0.10 & 0.30 & 1 & & & & & & & \\
\hline Size of & & & & & & & & & & \\
\hline Investment & 0.24 & 0.56 & $-0.17^{*}$ & 1 & & & & & & \\
\hline Tooling cost & 0.00 & 0.62 & $-0.11 *$ & $0.52 *$ & 1 & & & & & \\
\hline Potential Sales & -0.40 & 0.53 & $0.19 *$ & $-0.32 *$ & $-0.18^{*}$ & 1 & & & & \\
\hline $\begin{array}{l}\text { Manufacturing } \\
\text { Cost }\end{array}$ & 0.04 & 0.46 & $-0.15 *$ & $0.39 *$ & $0.36 *$ & $-0.22 *$ & 1 & & & \\
\hline Competition from & & & & & & & & & & \\
\hline Imitators & 0.09 & 0.55 & -0.07 & $0.12 *$ & 0.08 & 0.02 & 0.03 & 1 & & \\
\hline Uncertainty & 0.06 & 0.63 & $-0.19 *$ & $0.51 *$ & $0.35 *$ & $-0.26 *$ & $0.27^{*}$ & $0.12 *$ & 1 & \\
\hline Uncertainty & 0.02 & 0.51 & -0.05 & $0.15^{*}$ & 0.03 & $-0.21^{*}$ & $0.08^{*}$ & 0.04 & $0.15^{*}$ & 1 \\
\hline
\end{tabular}

Note.-Significance levels for correlations based on 2-tailed $t$-test.

* Statistically significant at the $1 \%$ level.

Table 4. Characteristics of Entrant versus Non-Entrant Inventions

\begin{tabular}{|c|c|c|c|c|c|}
\hline \multirow[b]{2}{*}{ Variable } & \multicolumn{2}{|c|}{ Non-Entrants } & \multicolumn{2}{|c|}{ Entrants } & \multirow{2}{*}{$\begin{array}{c}\text { Difference } \\
\text { Mean (Standard Error) }\end{array}$} \\
\hline & Mean & $\begin{array}{l}\text { Std. } \\
\text { Dev. }\end{array}$ & Mean & $\begin{array}{l}\text { Std. } \\
\text { Dev. }\end{array}$ & \\
\hline Size of Investment & 0.28 & 0.56 & -0.05 & 0.49 & $-0.32 * * *(0.06)$ \\
\hline Tooling cost & 0.02 & 0.62 & -0.20 & 0.56 & $-0.22 * * *(0.06)$ \\
\hline Potential Sales & -0.44 & 0.52 & -0.11 & 0.50 & $0.33 * * *(0.05)$ \\
\hline Manufacturing Cost & 0.06 & 0.46 & -0.17 & 0.43 & $-0.24 * * *(0.05)$ \\
\hline $\begin{array}{l}\text { Competition from } \\
\text { Imitators }\end{array}$ & 0.11 & 0.55 & -0.03 & 0.54 & $-0.13 * * \quad(0.06)$ \\
\hline $\begin{array}{l}\text { Development } \\
\text { Uncertainty }\end{array}$ & 0.10 & 0.62 & -0.29 & 0.56 & $-0.39 * * *(0.06)$ \\
\hline Demand Uncertainty & 0.03 & 0.52 & -0.05 & 0.47 & $-0.08(0.05)$ \\
\hline
\end{tabular}

Note.-Significance levels for differences in means use two-tailed $t$-tests. Based on 911 nonentrant and 101 entrant observations.

* Statistically significant at the $10 \%$ level.

** Statistically significant at the $5 \%$ level.

$* * *$ Statistically significant at the $1 \%$ level. 
Table 5. Determinants of Entry

Logit Dependent Variable: Entry ( 1 if Entered, 0 if Not)

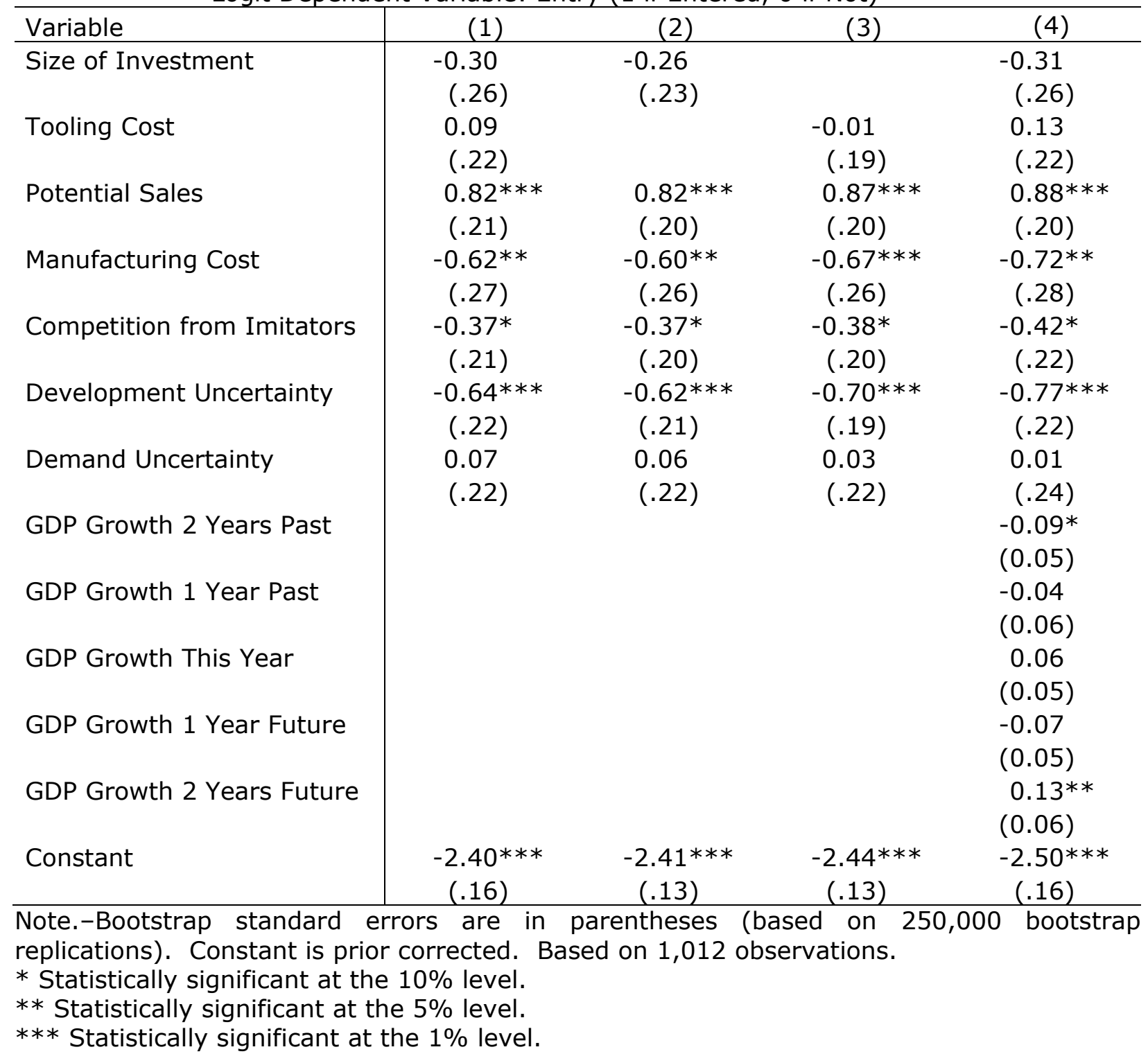


Table 6. Determinants of Exit

Dependent: Probability of Exit per Annum among Inventors Who Have Not Yet Exited

\begin{tabular}{l|cc}
\hline Variable & Weibull & Exponential \\
\hline Size of Investment & 0.07 & 0.09 \\
Tooling Cost & $(.53)$ & $(.53)$ \\
& -0.60 & -0.60 \\
Potential Sales & $(.45)$ & $(.46)$ \\
& 0.05 & 0.08 \\
Manufacturing Cost & $(.46)$ & $(.46)$ \\
& 0.37 & 0.39 \\
Competition from Imitators & $(.57)$ & $(.58)$ \\
& $0.97 * *$ & $1.00 * *$ \\
Development Uncertainty & $(.47)$ & $(.48)$ \\
& -0.61 & -0.62 \\
Demand Uncertainty & $(.42)$ & $(.42)$ \\
& 0.39 & 0.38 \\
Ln $(p)$ & $(.48)$ & $(.48)$ \\
& -0.09 & \\
Constant & $(.18)$ & $-2.76 * * *$ \\
& $-2.64 * * *$ & $(.33)$ \\
\hline Joint Significance of All & $(.40)$ & .048 \\
Economic Measures, $p$-val. & .059 & \\
\hline
\end{tabular}

Note.-Standard errors are in parentheses. Analysis accounts for right-censoring in the time to exit. Joint significance from likelihood ratio test. Based on 77 observations.

* Statistically significant at the $10 \%$ level. $* *$ Statistically significant at the $5 \%$ level. $* * *$ Statistically significant at the $1 \%$ level. 
Table 7. Reasons for Entry and Exit

\begin{tabular}{|c|c|c|c|c|}
\hline \multirow{4}{*}{$\begin{array}{l}\text { Panel } 1 . \text { Why did you not start selling the invention? } \\
\text { Pecuniary Reasons }\end{array}$} & \multicolumn{3}{|c|}{ Non-Entrants by IAP Reccomendation } & \multirow[b]{2}{*}{$\begin{array}{l}\text { Fisher's } \\
\text { exact test }\end{array}$} \\
\hline & All & Stop & Go & \\
\hline & Proportion & Proportion & Proportion & \\
\hline & & & & \\
\hline Innovation Centre recommended to stop & $42 \%$ & $48 \%$ & $16 \%$ & 0.00 \\
\hline Lack of capital & $32 \%$ & $30 \%$ & $39 \%$ & 0.00 \\
\hline Similar product already in the market & $22 \%$ & $23 \%$ & $17 \%$ & 0.13 \\
\hline Still working on product development & $18 \%$ & $16 \%$ & $23 \%$ & 0.85 \\
\hline Could not obtain patent or copyright & $11 \%$ & $11 \%$ & $12 \%$ & 0.88 \\
\hline Invention could not be produced at reasonable cost & $10 \%$ & $10 \%$ & $11 \%$ & 0.75 \\
\hline Expected sales volume was too low & $7 \%$ & $6 \%$ & $9 \%$ & 0.23 \\
\hline Found no buyer of the property rights & $8 \%$ & $7 \%$ & $14 \%$ & 0.02 \\
\hline Invention was not technically feasible & $8 \%$ & $8 \%$ & $5 \%$ & 0.28 \\
\hline Found better opportunities elsewhere & $5 \%$ & $4 \%$ & $7 \%$ & 0.06 \\
\hline Expected profit per unit too low & $6 \%$ & $6 \%$ & $6 \%$ & 1.00 \\
\hline \multicolumn{5}{|l|}{ Non-Pecuniary Reasons } \\
\hline Did not know how to proceed & $27 \%$ & $29 \%$ & $23 \%$ & 0.23 \\
\hline Family or personal reasons & $9 \%$ & $8 \%$ & $8 \%$ & 1.00 \\
\hline Did not want to commercialize & $6 \%$ & $5 \%$ & $10 \%$ & 0.07 \\
\hline Lost interest & $7 \%$ & $7 \%$ & $6 \%$ & 0.85 \\
\hline
\end{tabular}

Panel 2. Why did you stop selling the innovation?

Pecuniary Reasons

Sales volume was too low $\quad 31 \%$

\begin{tabular}{ll} 
Lack of capital & $3 \%$ \\
\hline
\end{tabular}

Found better opportunities elsewhere $\quad 14 \%$

$\begin{array}{ll}\text { Profit per unit too low } & 12 \%\end{array}$

Licensed or sold the right to sell it $\quad 10 \%$

Competition $4 \%$

Difficulty with access to distribution channel $\quad 4 \%$

$\begin{array}{ll}\text { Price pressure from competitors } & 0 \%\end{array}$

\section{Non-Pecuniary Reasons}

Family or personal reasons $12 \%$

\begin{tabular}{ll} 
Lost interest & $12 \%$ \\
\hline
\end{tabular}

Note.-Multiple reasons can be given, so columns do not total to $100 \%$. Base number of responses to each question varies between 641 and 1,363. The Fisher's exact test column reports the $p$-value for rejection of the null hypothesis that inventors in

the Stop and Go categories had the same probability of stating a given reason for non-entry. 